\title{
Assessment of Training Outcomes of Nurse Readers for Diabetic Retinopathy Telescreening: Validation Study
}

\author{
Marie Carole Boucher ${ }^{1 *}$, MD, FRCSC; Michael Trong Duc Nguyen ${ }^{2 *}$, MD; Jenny Qian ${ }^{3,4,5^{*}}$, MD \\ ${ }_{1}^{1}$ Maisonneuve-Rosemont Ophthalmology University Center, Department of Ophthalmology, Université de Montréal, Montreal, QC, Canada \\ ${ }^{2}$ Department of Ophthalmology, Université de Montréal, Montreal, QC, Canada \\ ${ }^{3}$ Department of Ophthalmology \& Vision Sciences, University of Toronto, Toronto, ON, Canada \\ ${ }^{4}$ Hamilton Regional Eye Institute, St Joseph's Healthcare Hamilton, Hamilton, ON, Canada \\ ${ }^{5}$ Division of Ophthalmology, Department of Surgery, McMaster University, Hamilton, ON, Canada \\ *all authors contributed equally
}

\section{Corresponding Author:}

Marie Carole Boucher, MD, FRCSC

Maisonneuve-Rosemont Ophthalmology University Center

Department of Ophthalmology

Université de Montréal

5415, de l'Assomption

Montreal, QC, H1T 2M4

Canada

Phone: 15142523400 ext 4959

Email: mariecarole@gmail.com

\begin{abstract}
Background: With the high prevalence of diabetic retinopathy and its significant visual consequences if untreated, timely identification and management of diabetic retinopathy is essential. Teleophthalmology programs have assisted in screening a large number of individuals at risk for vision loss from diabetic retinopathy. Training nonophthalmological readers to assess remote fundus images for diabetic retinopathy may further improve the efficiency of such programs.

Objective: This study aimed to evaluate the performance, safety implications, and progress of 2 ophthalmology nurses trained to read and assess diabetic retinopathy fundus images within a hospital diabetic retinopathy telescreening program.

Methods: In this retrospective interobserver study, 2 ophthalmology nurses followed a specific training program within a hospital diabetic retinopathy telescreening program and were trained to assess diabetic retinopathy images at 2 levels of intervention: detection of diabetic retinopathy (level 1) and identification of referable disease (level 2). The reliability of the assessment by level 1-trained readers in 266 patients and of the identification of patients at risk of vision loss from diabetic retinopathy by level 2-trained readers in 559 more patients were measured. The learning curve, sensitivity, and specificity of the readings were evaluated using a group consensus gold standard.

Results: An almost perfect agreement was measured in identifying the presence of diabetic retinopathy in both level 1 readers $(\kappa=0.86$ and 0.80$)$ and in identifying referable diabetic retinopathy by level 2 readers $(\kappa=0.80$ and 0.83$)$. At least substantial agreement was measured in the level 2 readers for macular edema $(\kappa=0.79$ and 0.88$)$ for all eyes. Good screening threshold sensitivities and specificities were obtained for all level readers, with sensitivities of $90.6 \%$ and $96.9 \%$ and specificities of $95.1 \%$ and $85.1 \%$ for level 1 readers (readers A and B) and with sensitivities of $86.8 \%$ and $91.2 \%$ and specificities of $91.7 \%$ and $97.0 \%$ for level 2 readers (readers A and B). This performance was achieved immediately after training and remained stable throughout the study.

Conclusions: Notwithstanding the small number of trained readers, this study validates the screening performance of level 1 and level 2 diabetic retinopathy readers within this training program, emphasizing practical experience, and allows the establishment of an ongoing assessment clinic. This highlights the importance of supervised, hands-on experience and may help set parameters to further calibrate the training of diabetic retinopathy readers for safe screening programs.
\end{abstract}

(JMIR Diabetes 2020;5(2):e17309) doi: 10.2196/17309 


\section{KEYWORDS}

training; teleophthalmology; telemedicine; diabetic retinopathy; screening; referral; nurse

\section{Introduction}

\section{Diabetic Retinopathy and Remote Screening}

Diabetic retinopathy is the main cause of legal and functional blindness in the working-age population and in many developed countries [1,2]. Timely identification of individuals with diabetes who are at risk [3] and early management of diabetic retinopathy significantly reduces the progression to blindness [4].

The use of teleophthalmology programs to detect diabetic retinopathy and manage follow-up has been shown to be cost-effective [5] and valuable [6-9]. However, there are also concerns about accurate diagnosis and treatment decisions by retina specialists or ophthalmologists [7,10-20]. Family physicians trained to assess diabetic retinopathy have shown good levels of agreement with retina specialists [21-23]. In an attempt to improve resource management and relieve the reading interpretation burden on ophthalmologists, various diabetic retinopathy screening programs have introduced nonphysician trained graders to identify patients at risk of vision loss from diabetic retinopathy [23-29]. Previous studies have discussed the sensitivity of human graders for referable disease [30,31] and the workload required for graders to maintain expertise [32]. However, the literature is scant on specific reader training, involving only small numbers of trainees [33], and outcomes are evaluated without training specifications [34]. To our knowledge, other than the UK training program [35], there is no set minimum practical experience required for training diabetic retinopathy readers, and none that specifically addresses the performance curve with training experience.

\section{Study Objectives}

This study aimed to evaluate the performance, safety implications, and progress of 2 ophthalmology nurses in detecting diabetic retinopathy and identifying referable diseases following specific training in a diabetic retinopathy telescreening program. Their reading results were compared with those obtained from a retina specialist and the gold standard, consisting of a group-arbitrated consensus. A secondary objective was to determine the reason for reading discrepancies.

This study identifies training parameters to help tailor and standardize the training of nonophthalmologist readers for safe diabetic retinopathy interpretation in a screening program and validates the individual and group performance of trainee readers within this program. However, as with any screening program, the need for continuous monitoring and education of readers after the training process remains necessary.

\section{Methods}

\section{Ethical Considerations}

This study is approved by the Institutional Suitability Committee, the Scientific Evaluation Committee and the Research Ethics Committee of the Centre Intégré Universitaire de Santé et de Services Sociaux de l'Est-de-l'île-de-Montréal,
Montreal, Québec, Canada, where it was conducted (US Federal Wide Assurance numbers FWA00001935 and IRB00002087).

\section{Study Population, Design, and Data Collection}

This retrospective interobserver reliability study was conducted on 829 patients with type 2 diabetes who attended a screening visit within a hospital-based teleophthalmology program at the Maisonneuve-Rosemont University Ophthalmology Center between February 2016 and September 2018. A total of 4 patients with laser scars from diabetic retinopathy treatment were mistakenly included in the program, who were excluded from the analysis; therefore, the final analysis was conducted on 825 individuals (1650 eyes). Patients were imaged by an ophthalmic photographer with a nonmydriatic camera (iCam-Optovue) after pupil dilation with $1 \%$ tropicamide to reduce ungradable imaging. Two 45 -degree image fields, 1 image centered on the disc and 2 centered on the macula, were obtained to ensure adequate macular imaging. Demographics were not collected.

The images were securely transmitted to a dedicated hospital server and accessed by all readers from a teleophthalmology diabetic retinopathy electronic platform (iVision from RetinaLabs), which allowed interpretation by various levels of readers. The images were reviewed nonstereoscopically at the capture resolution, with automated or manual image enhancement (magnification, brightness, and contrast) (Adobe Photoshop 7.0, Adobe Systems Inc). Images were assessed using a grading software that showed the grading scheme and the Early Treatment Diabetic Retinopathy Study (ETDRS) standard photographs as references at all times. The integrated grading scheme is based on the Scottish Diabetic Retinopathy Grading Scheme (2007) [36] described in Multimedia Appendix 1, which resembles that of the American Academy of Ophthalmology. It takes into account two 45-degree imaging fields and refers to the ETDRS standard photographs. In this program, the absence of any diabetic retinopathy leads to a 2-year imaging recommendation.

Through the teleophthalmology platform, level 1 readers determine for each eye, the image quality, if diabetic retinopathy is present (corresponding to $\geq \mathrm{R} 1$ ) or absent, and identify any other detected abnormalities. Level 2 readers determine image quality and grade diabetic retinopathy in 5 severity levels: no retinopathy (R0), mild (R1), moderate (R2), severe nonproliferative diabetic retinopathy $(\mathrm{R} 3)$, and proliferative diabetic retinopathy $(\mathrm{R} 4)$. They also specifically grade diabetic macular edema (DME) as none (M0), presence of any microaneurysm, hemorrhage, or exudate within 2 disc diameters (DD) of the fovea (M1), or within 1 DD of the fovea (M2). Any other abnormality was identified for ophthalmologic attention as well. Ungradable images are labeled as R6 for the general diabetic assessment and M6 for the macular assessment by all readers, which leads to an automatic referral for an in-person examination after validation by the level 3 reader (retina specialist). The level 3 reader (MB), who is blinded to the 
trained readers, rereads all of the images on the same teleophthalmology platform, acting as a level 1 or level 2 reader.

For teaching and quality assurance purposes, a weekly group review was attended by all 3 readers, where any discrepancies of level 1 or 2 readings with that of the level 3 reader generated by the built-in quality assurance module of the electronic reading platform, were discussed. The final consensus of any reading disagreements was determined by group arbitration, which was established as the gold standard.

\section{Training of the Readers}

Two ophthalmology nurses (A and B), 1 technical and 1 clinical, voluntarily participated in this study and were trained successively to intervene as level 1 and level 2 readers. Outside of training for visual acuity measurement and instillation of dilating eye drops, they had no relevant experience or credentials in assessing diabetic retinopathy or prior involvement in any eye imaging.

The training of level 1 reading was provided by a validated interactive electronic platform [37] assuming no prior knowledge or background on diabetic retinopathy. The platform teaches the characteristic features of normal fundi, those of diabetic retinopathy, and the recognition of image quality. It allows the graders to grade in one or multiple sessions and lasts a total of about 3 hours. The training is concluded by a self-assessment quiz on 50 diabetic patients (100 eyes), of which $60 \%(30 / 50)$ had some diabetic retinopathy and were further subdivided as $80 \%(24 / 30) \mathrm{R} 1,10 \%$ (3/30) R2, 3\% (1/30) R3, and 6\% (2/30) $\mathrm{R} 4 ; 28 \%(14 / 50)$ had no diabetic retinopathy and $12 \%(6 / 50)$ showed insufficient image quality to allow reading. The self-assessment is performed in 1 session without any time limit, although it generally lasts about 2 hours. An arbitrary 80\% success threshold allows access to level 1 reading with ongoing quality control by the retina specialist.

Training for level 2 reading involves weekly sessions of quality assurance and group reviews of all new level 1 individual readings. This enables progressive recognition of diabetic retinopathy severity, which leads to a referral to a level 3 reader (retina specialist if the severity is $>\mathrm{R} 2$ (exceeds a moderate level of retinopathy) or $\geq \mathrm{M} 2$ (possible DME within 1 DD from the fovea. The precautionary referral of any uncertain or unusual findings, such as other pathology or atypical variation of normal characteristics, is emphasized.

The level 1 readers spontaneously reported feeling comfortable for level 2 reading after the group review and training on 266 imaged patients (532 eyes), of which reader A had individually assessed 114 patients and reader B, 152 patients. This was set as the starting point for the evaluation of their next readings for a total of 1118 level 2 eye readings in 559 patients (323 patients for reader $\mathrm{A}$ and 236 for reader $\mathrm{B}$ ).

\section{Statistical Analysis}

The kappa ( $\kappa)$ statistic based on the Landis and Koch system [38] evaluates the reliability of the assessment beyond that of chance for the level 1 and level 2 readings in all readers against the consensus gold standard. It also evaluates the level 3 reader's reliability for each level 1 and 2 cohort and to the gold standard; 95\% CIs were used, and $P$ values of <.001 were considered significant.

The screening performance (sensitivity and specificity), diagnostic accuracy $(95 \% \mathrm{CI})$, and the learning curve in 50-patient strata of the level 1 and level 2 readers were calculated with the consensus gold standard readings as those of the level 3 reader with respect to each level 1 and level 2 cohorts. Grading of the most affected eye was used to calculate the sensitivity and specificity of the patient readings.

\section{Results}

\section{Demographics}

There were 532 eyes (266 patients) evaluated at the level 1 reading level, of which level 1 reader $\mathrm{A}$ and reader $\mathrm{B}$ individually assessed 228 eyes (114 patients) and 304 eyes (152 patients), respectively. A total of 1118 eyes (559 patients) were assessed by the level 2 readers, which also included an evaluation for DME, and of which level 2 reader A and reader $\mathrm{B}$ assessed 646 eyes ( 323 patients) and 472 eyes (236 patients), respectively.

Excluding any ungradable images as per the consensus gold standard, the global prevalence of diabetic retinopathy $(\geq \mathrm{R} 1)$ was $46.2 \%(117 / 254)$ and $37.3 \%(196 / 526)$ in the level 1 and level 2 cohorts, respectively, and the total prevalence of diabetic macular involvement was $25.8 \%$ (135/523). The prevalence and distribution of disease severity and number of ungradable images were comparable between level 1 and level 2 cohorts and between reader $\mathrm{A}$ and $\mathrm{B}$ according to the consensus gold standard grading (Multimedia Appendix 2). They were also comparable for diabetic retinopathy severity, DME, and ungradable imaging in each individual level reader (Multimedia Appendices 3-5).

\section{Referral Reasons}

The most common reason for referral was DME (102/151, $67.5 \%)$, followed by severe diabetic retinopathy with DME $(11 / 151,7.3 \%)$, and severe diabetic retinopathy without DME (2/151, 1.3\%; Table 1). DME represented 76\% (70/92) and 57\% $(38 / 67)$ of the level 2 reader A and B referrals, respectively, and $72 \%(57 / 79)$ and $58 \%(36 / 62)$ of those of the retina specialist with respect to the level 2 reader images.

The kappa values in Table 2 show good agreement for referable disease in all eye readings and for all level readers. There is almost perfect agreement in identifying the presence of diabetic retinopathy by level 1 readers $(\kappa=0.86$ and 0.80$)$ and in identifying referable disease $(>R 2)$ by level 2 readers $(\kappa=0.80$ and 0.83 ), compared with the gold standard. At least substantial agreement was measured in level 2 readers versus the gold standard for macular edema $(\mathrm{M}>1 ; \kappa=0.79$ and 0.88$)$ as well as for deciding if a referral to ophthalmology was warranted ( $\kappa=0.76$ and 0.89 ). The level 3 reader, acting as a level 2 reader, achieved an almost perfect agreement with kappa values of 0.95 , 0.95 , and 0.95 for referable retinopathy, DME, and decision to refer to ophthalmology, respectively. 
Table 1. Reasons for diabetic retinopathy referral in level 2 and level 3 readers and the consensus gold standard (N=559).

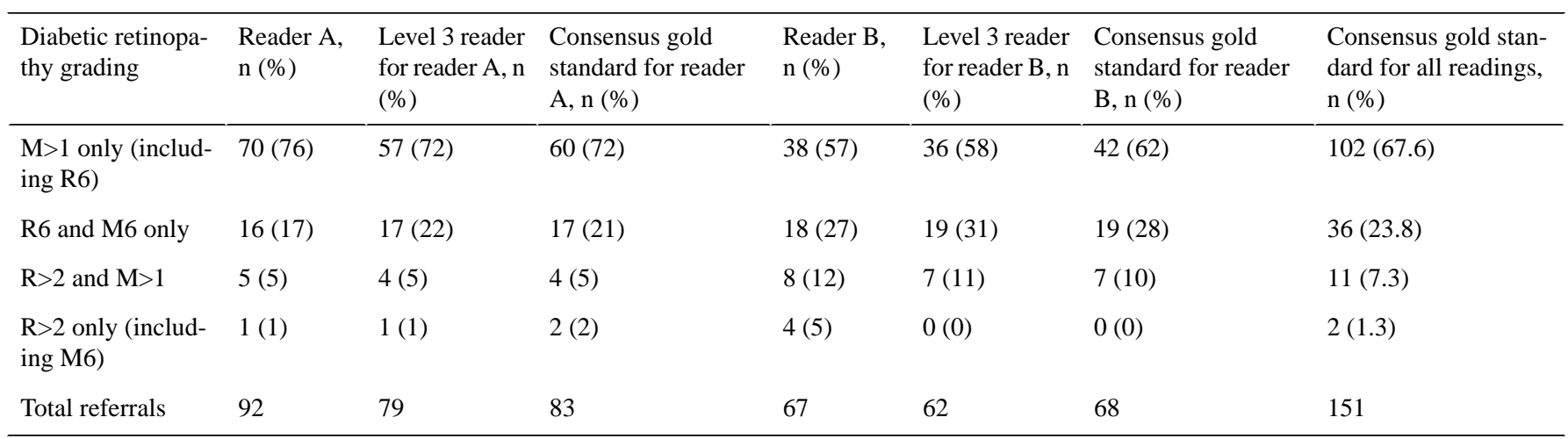

Table 2. Agreements of level 1,2, and 3 readings for referable ( $>$ R2) diabetic retinopathy and diabetic macular edema ( $>$ M1) and referral to ophthalmology for all eyes versus the consensus gold standard (level 1 reading [ $n=266]$ and level 2 reading $[n=1118]$ ).

\begin{tabular}{|c|c|c|c|}
\hline Reader & $\begin{array}{l}\text { Consensus gold standard referable } \\
\text { diabetic retinopathy, } \kappa^{\mathrm{a}}(95 \% \mathrm{CI})\end{array}$ & $\begin{array}{l}\text { Consensus gold standard referable dia- } \\
\text { betic macular edema grading, } \kappa(95 \% \\
\text { CI })\end{array}$ & $\begin{array}{l}\text { Consensus gold standard referral to } \\
\text { ophthalmology, } \kappa(95 \% \mathrm{CI})\end{array}$ \\
\hline \multicolumn{4}{|l|}{ Level 1 reading $(n=266)$} \\
\hline Reader A $(n=114)$ & $\mathrm{N} / \mathrm{A}^{\mathrm{b}}$ & N/A & $0.859(0.764-0.953)$ \\
\hline Level 3 reader for reader $A$ & N/A & N/A & $1.00(1.000-1.000)$ \\
\hline Reader B (n=152) & N/A & N/A & $0.803(0.709-0.896)$ \\
\hline Level 3 reader for reader $B$ & N/A & $\mathrm{N} / \mathrm{A}$ & $1.00(1.000-1.000)$ \\
\hline \multicolumn{4}{|l|}{ Level 2 reading $(n=1118)$} \\
\hline Reader A $(n=646)$ & $0.803(0.757-0.850)$ & $0.788(0.733-0.842)$ & $0.757(0.677-0.838)$ \\
\hline Level 3 reader for reader $A$ & $0.940(0.912-0.968)$ & $0.961(0.935-0.986)$ & $0.967(0.935-0.999)$ \\
\hline Level 3 reader for reader $B$ & $0.957(0.930-0.983)$ & $0.946(0.914-0.979)$ & $0.936(0.886-0.987)$ \\
\hline
\end{tabular}

${ }^{\mathrm{a}}$ K: kappa coefficient. All kappas have $P$ values $<.001$.

${ }^{\mathrm{b}}$ Not applicable.

\section{Reader Agreements and Referrals}

With respect to the cohorts, good screening threshold sensitivities and specificities were obtained in all level readers (Table 3), with sensitivities of $91 \%$ and $97 \%$ and specificities of $95 \%$ and $85 \%$ for level 1 readers $\mathrm{A}$ and $\mathrm{B}$, and sensitivities of $86.8 \%$ and $91.2 \%$ and specificities of $91.7 \%$ and $97.0 \%$ for level 2 readers. Reader B achieved slightly better sensitivities than reader $\mathrm{A}$, and the level 3 reader achieved the highest sensitivity and specificity.

Table 3. Sensitivity and specificity for the identification of patient referrals by each reader versus the consensus gold standard.

\begin{tabular}{llll}
\hline Reader & Number of patients, $\mathrm{n}$ & Sensitivity, \% (95\% CI) & Specificity, \% (95\% CI) \\
\hline Level 1 reading (n=266) & 114 & $91(82.70-98.44)$ & $95(89.66-100.51)$ \\
$\quad$ Reader A & 114 & $100(100-100)$ & $100(100-100)$ \\
$\quad$ Level 3 reader for reader A & 152 & $97(92.72,101.12)$ & $85(77.57-92.55)$ \\
$\quad$ Reader B & 152 & $100(100-100)$ & $100(100-100)$ \\
$\quad$ Level 3 reader for reader B & 323 & & $91.7(88.17-95.16)$ \\
Level 2 reading (n=559) & 323 & $96.8(79.45-94.04)$ & $100(100-100)$ \\
$\quad$ Reader A & 236 & $95.2(90.57-99.790)$ & $97.0(94.45-99.59)$ \\
$\quad$ Level 3 reader for reader A & 236 & $91.2(84.43-97.92)$ & $100(100-100)$ \\
Reader B & & & \\
Level 3 reader for reader B &
\end{tabular}


Level 2 and 3 reading discrepancies with the consensus gold standard and their impact on patient management are described in Table 4. Both level 2 readers show a higher overall patient disagreement rate with the consensus gold standard $(66 / 323$, $20.4 \%$ and $42 / 236,17.8 \%)$ than the level 3 reader $(18 / 323,5.6 \%$ and $14 / 236,5.9 \%$ ), respectively, but a high proportion of the level 2 reader disagreements (57/66, 86\% and 36/42, 86\% respectively) had only minor or no impact on patient management.

A missed referral to ophthalmology is considered a significant misreading and occurred in 2.8\% (9/323) and 2.5\% (6/236) of patients in the level 2 readings, respectively, and respective to these cohorts, in $1.2 \%(4 / 323)$ and $2.5 \%(6 / 236)$ of patients in the level 3 readings. A comparable rate of significant misreading (excluding underappreciation of image quality) is shown in both level 2 readers $(6 / 323,1.9 \%$ and $5 / 236,2.1 \%$, respectively for reader A and reader B) and level 3 readers (4/323, 1.2\% and $6 / 236,2.5 \%$ ). All image misreadings were related to unrecognized isolated microaneurysms located within $1 \mathrm{DD}$ of the fovea in the absence of any exudate, except for 1 eye with neovascularization misinterpreted as an epiretinal membrane by the level 3 reader and confirmed on clinical examination.
Level 2 readers also show an overall underappreciation of ungradable imaging in $1.2 \%(4 / 323)$ and $0.8 \%(2 / 236)$ of the patients, respectively for reader A and reader B. Stratified analysis of 50 successive patients showed that as experience was gained, this rate was still maintained.

The consequences of misreading on patient management, such as the timing of new imaging or referral for in-person examination, were measured to be $73 \%(48 / 66)$ and $55 \%(23 / 42)$ in the level 2 reader cohorts, respectively, and in $67 \%(12 / 18)$ and $64 \%(9 / 14)$ of the level 3 reader, respectively, in the level 2 cohort.

Both level 2 readers tended to be more conservative in their actions, with $6.5 \%(21 / 323)$ and $2.1 \%$ (5/236) unnecessary referral recommendations, as compared with $0 \%$ for the level 3 reader, reimaging sooner than indicated in $4.3 \%$ (14/323) and $4.7 \%(11 / 236)$ of patients, respectively. Both level 2 readers acknowledged possible unnecessary referrals, but still referred patients as a precaution in $1.2 \%(4 / 323)$ and $0.4 \%(1 / 236)$ of all screenings, respectively, which represented $6 \%(4 / 66)$ and $2 \%(1 / 42)$ of their misreads.

Table 4. Level 2 and level 3 reader disagreements according to the consensus gold standard and impact on patient management $(\mathrm{N}=559)$.

\begin{tabular}{|c|c|c|c|c|}
\hline Effect of disagreement & $\begin{array}{l}\text { Reader A (n=323), } \mathrm{n} \\
(\%)\end{array}$ & $\begin{array}{l}\text { Level } 3 \text { reader for reader } \\
\mathrm{A}(\mathrm{n}=323), \mathrm{n}(\%)\end{array}$ & $\begin{array}{l}\text { Reader B }(\mathrm{n}=236), \mathrm{n} \\
(\%)\end{array}$ & $\begin{array}{l}\text { Level } 3 \text { reader for } \\
\text { reader } B(n=236), n \\
(\%)\end{array}$ \\
\hline No impact on patient management & $18(5.6)$ & $6(1.9)$ & $19(8.1)$ & $5(2.1)$ \\
\hline Impact on patient management & $48(14.9)$ & $12(3.7)$ & $23(9.8)$ & $9(3.8)$ \\
\hline Total number of disagreements & $66(20.4)$ & $18(5.6)$ & $42(17.8)$ & $14(5.9)$ \\
\hline No referral although indicated & $9(2.8)$ & $4(1.2)$ & $6(2.5)$ & $6(2.5)$ \\
\hline Unnecessary referral & $21(6.5)$ & $0(0)$ & $5(2.1)$ & $0(0)$ \\
\hline Imaging recommended sooner than necessary & $14(4.3)$ & $0(0)$ & $11(4.7)$ & $1(0.4)$ \\
\hline Imaging recommended later than indicated & $4(1.2)$ & $8(2.5)$ & $1(0.4)$ & $2(0.9)$ \\
\hline \multicolumn{5}{|c|}{ Significant misreads (no referral although indicated) } \\
\hline $\begin{array}{l}\text { Missed isolated microaneurysm within } 1 \\
\mathrm{DD}^{\mathrm{a}} \text { of the fovea. }\end{array}$ & $6(1.9)$ & $3(0.9)$ & $5(2.1)$ & $6(2.5)$ \\
\hline $\begin{array}{l}\text { Confusion of neovascularization with an } \\
\text { epiretinal membrane }\end{array}$ & $0(0)$ & $1(0.3)$ & $0(0)$ & $0(0)$ \\
\hline Under appreciation of ungradable imaging & $3(0.9)$ & $0(0)$ & $1(0.4)$ & $0(0)$ \\
\hline \multicolumn{5}{|l|}{ Nonsignificant misreads } \\
\hline $\begin{array}{l}\text { Misreads with minimal impact on manage- } \\
\text { ment }\end{array}$ & $34(10.5)$ & $8(2.5)$ & $15(6.4)$ & $3(1.3)$ \\
\hline Referrals as a precaution & $4(1.2)$ & $0(0)$ & $1(0.4)$ & $0(0)$ \\
\hline Under appreciation of ungradable imaging & $1(0.3)$ & $0(0)$ & $1(0.4)$ & $0(0)$ \\
\hline
\end{tabular}

${ }^{\mathrm{a}} \mathrm{DD}$ : disc diameter.

\section{Learning Curve of Trained Readers}

The per-strata sensitivities and specificities of level 1 and level 2 readers show high sensitivity and specificity for all readers, achieved immediately after training to detect any presence of diabetic retinopathy for level 1 readers and, for level 2 readers, to identify referable disease (>R2 and/or $>\mathrm{M} 1$ ), which were maintained throughout the study (Multimedia Appendices 6 and 7).

Figures 1 and 2 show the cumulative incidence of misreads with time and gained experience to be more related to specificity 
than sensitivity issues. The small number of disagreements in for disagreements as more experience is gained. each stratum impedes the analysis of tendencies for the reasons

Figure 1. The cumulative incidence curve of misreadings for level 2 reader A image readings.

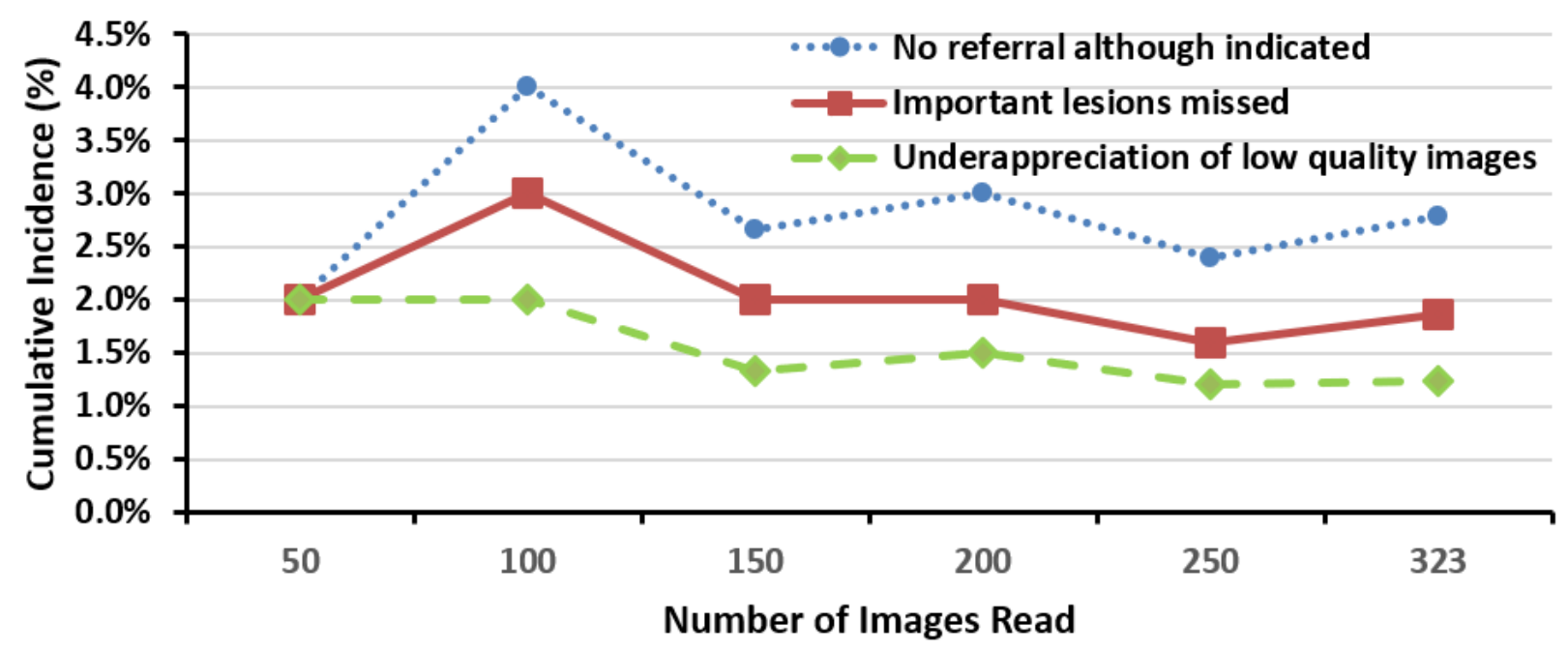

Figure 2. The cumulative incidence curve of misreadings for level 2 reader B image readings.

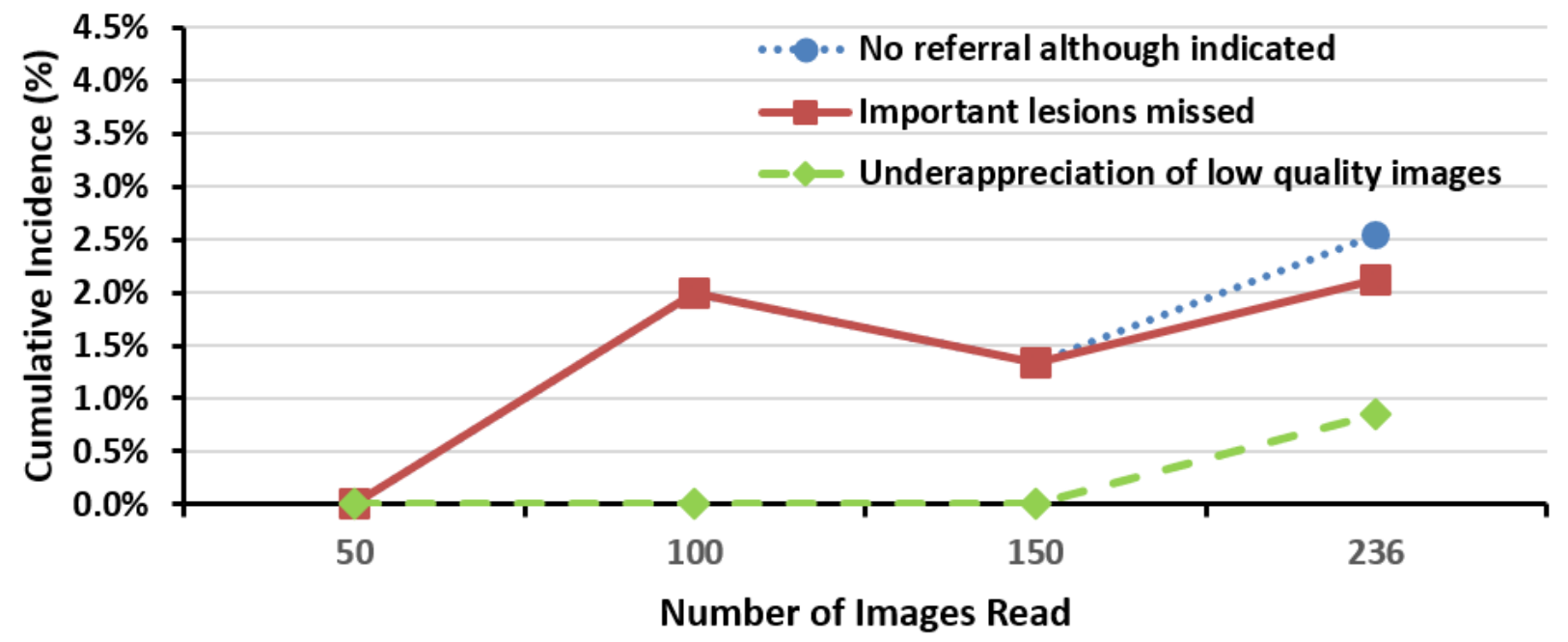

\section{Discussion}

\section{Principal Findings}

This study emphasizes the importance of practical experience and validates the screening performance and training of level 1 and level 2 diabetic retinopathy readers within this program. It may thus help set parameters to further calibrate the training of diabetic retinopathy readers for safe screening programs.

It shows $91 \%$ and $97 \%$ sensitivities, and $95 \%$ and $85 \%$ specificities in detecting any diabetic retinopathy, and $86.8 \%$ and $91.2 \%$ sensitivities, and $91.7 \%$ and $97.0 \%$ specificities in the identification of sight-threatening disease relative to the cohorts. These results are comparable to those reported in studies with similar conditions [33,39-42]. There is substantial overall intergrader agreement obtained by the 2 level 2 readers across all grading episodes for all referable retinopathy $(\kappa=0.757,95 \%$ CI $0.677-0.838$ and $\kappa=0.887,95 \%$ CI $0.822-0.952$, respectively).
Although inferior to those of the retina specialist $(\kappa=0.967$, $95 \%$ CI $0.935-0.999$ and $\kappa=0.936,95 \%$ CI $0.886-0.987)$, they compare favorably with the results by Goatman et al $(\kappa$ median 0.78 , interquartile range $0.70-0.84$ ) [42] who also used a consensus reading gold standard and similar diabetic retinopathy severity grading and outcome schemes and who achieved $95.3 \%$ sensitivities for referable diabetic retinopathy. In a quality assurance audit of 6 trained graders, Patra et al [43] found a strong agreement between graders and the retina specialist reference standard with a kappa of 0.7. This study's kappa values were greater than those reported by Patra et al [43] and exceeded their $80 \%$ set audit standards for interobserver agreement.

Ruamviboonsuk et al [33] trained 3 reading photographers and 3 ophthalmology nurses in a 2-day course, which showed only fair agreement with the 3 retina specialists consensus group regarding retinopathy severity, macular edema, and referrals. They concluded that this course was insufficient to adequately 
train nonphysicians in the appropriate reading skills. In contrast, the practical training of this study is extensive, and the graders of the Bhargava et al study underwent a 1-year rigorous training with regular auditing [41]. It is noteworthy that the graders of our study showed a high appreciation of the quality assurance and teaching procedures in their training.

Although not consistently met in many studies evaluating gold standards in diabetic retinopathy detection [30], targets of $80 \%$ and $90 \%$ to $95 \%$ sensitivity and specificity are recommended for diabetic retinopathy assessment by trained examiners $[44,45]$. The challenge of finding an appropriate gold standard in the grading of diabetic retinopathy, especially in ambiguous gradings, was met in our study by establishing a group-consensus arbitration gold standard. Although differences in diabetic retinopathy grading systems and reference gold standards complicate the comparisons, the previous authors also found a strong agreement between the graders and the retina specialist reference standard and concluded that trained nonphysician graders can provide high levels of accuracy in diabetic retinopathy and maculopathy detection and assessment.

Certification training programs, such as that of the United Kingdom National Health Service, suggest that good reading performance indicates good training but does not address minimal practical training experience for readers $[32,46]$. This study addresses the latter and found that practical training of level 1 readers on a teaching electronic platform and self-assessment on 50 patients resulted in a high intergrader agreement and high sensitivity and specificity rates for detecting diabetic retinopathy and identifying ungradable images, approaching those of the retina specialist and gold standard. Further training for referable diabetic retinopathy and macular edema through a group review of 532 eyes in 266 patients led to an immediate high agreement and sensitivity and specificity for this task, which was maintained in the next readings of 646 eyes in 323 patients and 472 eyes in 236 patients, respectively. This may be used as a threshold for similar practical training experience for nonophthalmologist diabetic retinopathy graders to meet quality standards in similar individuals and settings.

The failure of level 2 readers to recognize inadequate imaging under pupil dilation in $1.2 \%(4 / 323)$ and $0.8 \%(2 / 236)$ of all readings, respectively, represented $6 \%(4 / 66)$ and $5 \%(2 / 42)$ of all of their disagreements with the gold standard. In comparison, Farley et al [22] showed that $5.2 \%$ of eyes with inadequate imaging failed to be referred by trained primary care clinician readers in a study with a high rate of inadequate imaging due to nondilating pupils (29\%). Although the readers of this study were provided objective gradable image guidelines, possible borderline-quality images could have led to subjective assessments. Failure to recognize inadequate imaging underlines the importance of pursuing reader education and regular monitoring. The underappreciation of ungradable images in our study is in contrast with that of Ruamviboonsuk et al, who interpreted their high proportion of ungradable images as a lack of confidence in reading rather than true image ambiguity [33].

Level 2 readers made more conservative assessments, resulting in precautionary referrals in $1.2 \%(4 / 323)$ and $0.4 \%(1 / 236)$ of their readings versus none of the level 3 readings. Although these rates are small, further training to recognize unusual variants of normal and those having to be brought to the attention of the ophthalmologist as a precaution may help increase specificity and further reduce the workload on ophthalmologists.

Significant misreads causing missed referrals to ophthalmology were all related to missed isolated microaneurysms located within $1 \mathrm{DD}$ of the fovea in the absence of any exudate, except for 1 level 3 reader misinterpretation of neovascularization as an epiretinal membrane. An isolated microaneurysm within 1 DD of the fovea does not signal DME unless associated with a positive optical coherence tomography establishing edema, but does signal a potential risk of DME with time. Missed detection of possible DME was found to be the worst scenario in $1.9 \%$ $(6 / 323)$ and $2.1 \%(5 / 236)$ of level 2 reader significant misreads and in $0.9 \%(3 / 323)$ and $2.5 \%(6 / 236)$ of those of the level 3 reader. Level 2 readers appear to have greater sensitivity in detecting these isolated microaneurysms, as these misreadings represent $9 \%(6 / 66)$ and $12 \%(5 / 42)$ of all of their disagreements with the gold standard in comparison to $17 \%(3 / 18)$ and $36 \%$ $(5 / 14)$ of those of level 3 respective to the cohorts. Moss et al [47] similarly showed that most disagreements with all level readers are related to the nondetection of isolated microaneurysms in very mild disease states.

DME was the major cause of referral in this study at $65 \%$ of all referrals, followed by $8.2 \%$ for severe diabetic retinopathy with DME and $1 \%$ for severe diabetic retinopathy without DME.

Although overall screening posed no visual safety threat in $98.0 \%(548 / 559)$ of patients assessed by the level 2 readers $(317 / 323,98.1 \%$ and $231 / 236,97.9 \%$, respectively) and $98.2 \%$ (549/559) of all level 3 readings, a small number could be put at risk with this process. The majority were related to difficult positive identification of isolated microaneurysms in the macular area at the limit of detection, which often resulted in arbitration for the final gold standard grading. These could potentially and eventually be resolved with the use of greater resolution cameras for screening. Recommendations for reimaging later than required could represent some level of risk in 1.2\% (4/323) and $0.4 \%(1 / 236)$ of the patients assessed by the level 2 readers compared with those of the level 3 reader. Figure 3 shows images of 2 challenging cases of an isolated microaneurysm near the fovea. 
Figure 3. Two challenging cases of an isolated microaneurysm near the fovea. Arrows are used to indicate the location of microaneurysms.
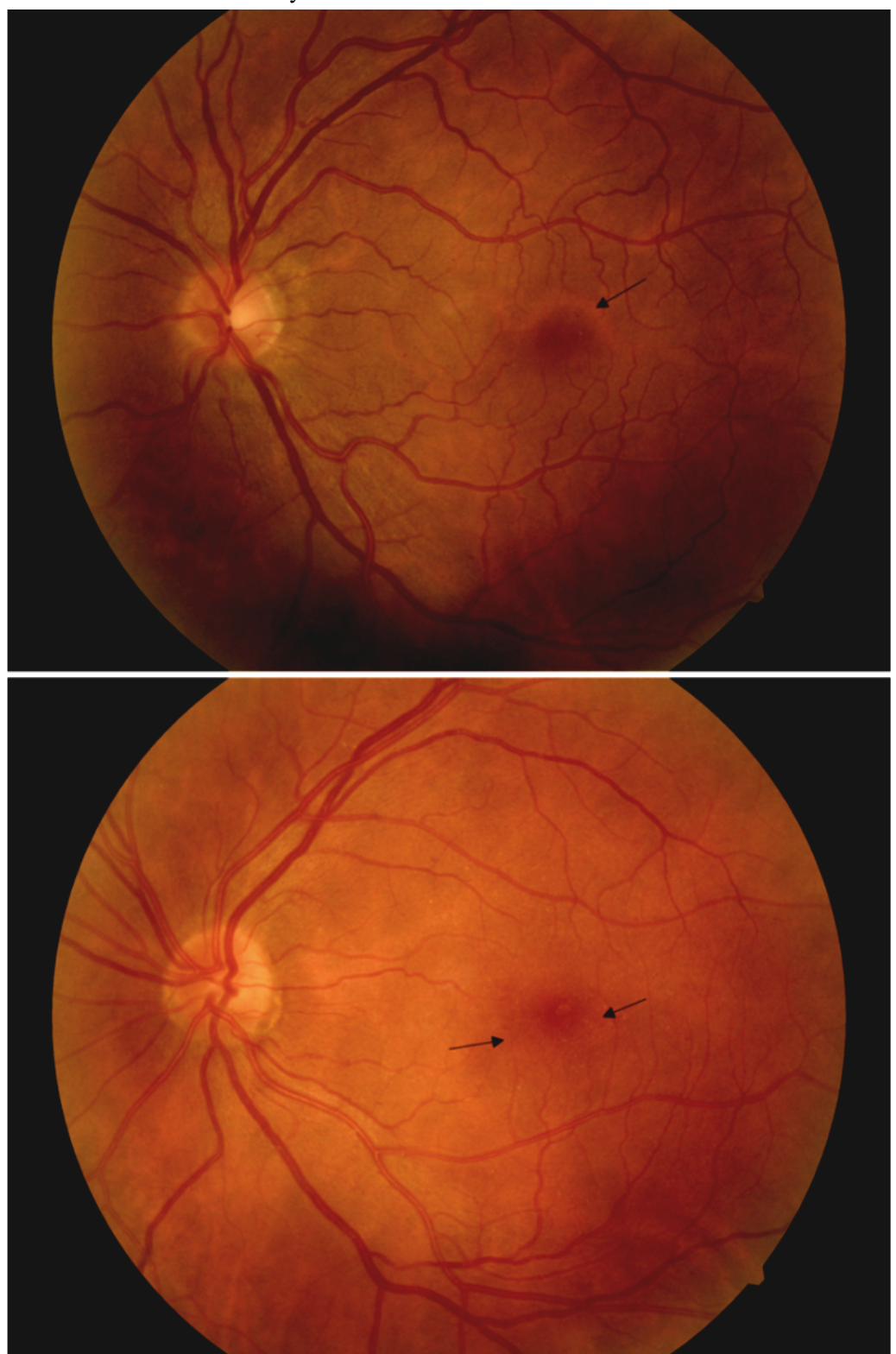

This study outperforms the screening results of Oke et al [48] showing that human readers miss $11 \%$ of sight-threatening diabetic retinopathy. They also conclude that low-grade-diabetic retinopathy misclassification is not uncommon but unlikely to lead to significant referral delays in sight-threatening diabetic retinopathy. The management of the small number of patients in whom a significant lesion is missed in 1 eye is also dependent upon the presence of other abnormalities in that eye or the other eye. As such, it cannot be shown if these patients would be referred had these lesions been present in an isolated state.

\section{Limitations}

Limitations of this study include its retrospective nature and the small number of trained readers, which only validates the individual and group performance of these readers within this specific training. These results may not apply to a larger reading group where possible individual performance variations could occur.

\section{Conclusions}

This study validates the screening performance and accuracy of the specific training of 2 nonphysician graders as level 1 (triage) and level 2 (referable diabetic retinopathy) graders who achieved a very high initial agreement that was maintained throughout the study and whose image interpretations compared favorably with that of a retina specialist and the consensus gold standard. It adds new information to scant literature on diabetic retinopathy reader training modalities, emphasizes the importance of training experience for reading, and suggests a starting threshold in a similar setting to train nonophthalmologist readers and meet quality standards. As with other studies $[39,49]$, it supports the need for continual performance monitoring and education of diabetic retinopathy readers after their training to guarantee ongoing high standards expected in any diabetic retinopathy screening service. Although this study allows the establishment of an ongoing diabetic retinopathy assessment clinic with these readers, it only describes the results of 2 individual readers and possible significant individual performance variations could occur in larger trainee groups. 


\section{Acknowledgments}

The following individuals are the members of the Trained Reader Screening for Diabetic Retinopathy Study Group: Dr MC Boucher, Technical Nurse Céline Bugeaud, Clinical Nurse Annie Croteau, First Year Ophthalmology Resident Michael Trong Duc Nguyen.

\section{Conflicts of Interest}

None declared.

\section{Multimedia Appendix 1}

Summary of the Scottish Diabetic Retinopathy Grading Scheme 2007 v1.1.

[PNG File , 49 KB-Multimedia Appendix 1]

\section{Multimedia Appendix 2}

Patient distribution of disease severity according to the worst eye and ungradable imaging between reader A and B, according to gold standard grading.

[PNG File, 30 KB-Multimedia Appendix 2]

\section{Multimedia Appendix 3}

Diabetic retinopathy findings and ungradable imaging in level 1 and level 3 readers and in the consensus gold standard. [PNG File, $21 \mathrm{~KB}-$ Multimedia Appendix 3]

\section{Multimedia Appendix 4}

Findings and prevalence of diabetic retinopathy severity, diabetic macular edema, and ungradable imaging in patients by individual readers in level 2 and level 3 readings and the consensus gold standard.

[PNG File, 46 KB-Multimedia Appendix 4]

\section{Multimedia Appendix 5}

Findings and prevalence of diabetic retinopathy severity, diabetic macular edema, and ungradable imaging by individual readers for all eyes imaged in level 2 and level 3 readings and the consensus gold standard.

[PNG File, 45 KB-Multimedia Appendix 5]

\section{Multimedia Appendix 6}

Per-strata sensitivities and specificities of level 2 readers for every patient as determined by the eye with the worst grading severity. [PNG File, $11 \mathrm{~KB}-\underline{\text { Multimedia Appendix 6] }}$

\section{Multimedia Appendix 7}

Per-strata sensitivities and specificities of level 2 readers for all eyes.

[PNG File, 12 KB-Multimedia Appendix 7]

\section{References}

1. Ding J, Wong TY. Current epidemiology of diabetic retinopathy and diabetic macular edema. Curr Diab Rep 2012 Aug;12(4):346-354. [doi: 10.1007/s11892-012-0283-6] [Medline: 22585044]

2. Yau JW, Rogers SL, Kawasaki R, Lamoureux EL, Kowalski JW, Bek T, Meta-Analysis for Eye Disease (META-EYE) Study Group. Global prevalence and major risk factors of diabetic retinopathy. Diabetes Care 2012 Mar;35(3):556-564 [FREE Full text] [doi: 10.2337/dc11-1909] [Medline: 22301125]

3. American Diabetes Association. Standards of medical care in diabetes--2012. Diabetes Care 2012 Jan;35(Suppl 1):S11-S63 [FREE Full text] [doi: 10.2337/dc12-s011] [Medline: 22187469]

4. Harvey JN, Craney L, Nagendran S, Ng CS. Towards comprehensive population-based screening for diabetic retinopathy: operation of the North Wales diabetic retinopathy screening programme using a central patient register and various screening methods. J Med Screen 2006;13(2):87-92. [doi: 10.1258/096914106777589669] [Medline: 16792832]

5. Javitt JC, Canner JK, Sommer A. Cost effectiveness of current approaches to the control of retinopathy in type I diabetics. Ophthalmology 1989 Feb;96(2):255-264. [doi: 10.1016/s0161-6420(89)32923-x] [Medline: 2495499] 
6. Coroando A. Western University Electronic Thesis and Dissertation. London, ON: The University of Western Ontario; 2014. Diagnostic Accuracy of Tele-ophthalmology for Diabetic Retinopathy Assessment: A Meta-analysis and Economic Analysis. Master's thesis URL: https://ir.lib.uwo.ca/etd/2282/ [accessed 2020-03-26]

7. Whited JD. Accuracy and reliability of teleophthalmology for diagnosing diabetic retinopathy and macular edema: a review of the literature. Diabetes Technol Ther 2006 Feb;8(1):102-111. [doi: 10.1089/dia.2006.8.102] [Medline: 16472057]

8. Sharp PF, Olson J, Strachan F, Hipwell J, Ludbrook A, O'Donnell M, et al. The value of digital imaging in diabetic retinopathy. Health Technol Assess 2003;7(30):1-119 [FREE Full text] [doi: 10.3310/hta7300] [Medline: 14604499]

9. Kim J, Driver DD. Teleophthalmology for first nations clients at risk of diabetic retinopathy: a mixed methods evaluation. JMIR Med Inform 2015 Feb 23;3(1):e10 [FREE Full text] [doi: 10.2196/medinform.3872] [Medline: 25705814]

10. Gupta SC, Sinha SK, Dagar AB. Evaluation of the effectiveness of diagnostic \& management decision by teleophthalmology using indigenous equipment in comparison with in-clinic assessment of patients. Indian J Med Res 2013 Oct;138(4):531-535 [FREE Full text] [Medline: 24434260]

11. Bursell SE, Cavallerano JD, Cavallerano AA, Clermont AC, Birkmire-Peters D, Aiello LP, Joslin Vision Network Research Team. Stereo nonmydriatic digital-video color retinal imaging compared with Early Treatment Diabetic Retinopathy Study seven standard field 35-mm stereo color photos for determining level of diabetic retinopathy. Ophthalmology 2001 Mar;108(3):572-585. [doi: 10.1016/s0161-6420(00)00604-7] [Medline: 11237913]

12. Boucher MC, Gresset JA, Angioi K, Olivier S. Effectiveness and safety of screening for diabetic retinopathy with two nonmydriatic digital images compared with the seven standard stereoscopic photographic fields. Can J Ophthalmol 2003 Dec;38(7):557-568. [doi: 10.1016/s0008-4182(03)80109-6] [Medline: 14740797]

13. Boucher MC, Desroches G, Garcia-Salinas R, Kherani A, Maberley D, Olivier S, et al. Teleophthalmology screening for diabetic retinopathy through mobile imaging units within Canada. Can J Ophthalmol 2008 Dec;43(6):658-668. [doi: 10.3129/i08-120] [Medline: 19020631]

14. Gómez-Ulla F, Fernandez MI, Gonzalez F, Rey P, Rodriguez M, Rodriguez-Cid MJ, et al. Digital retinal images and teleophthalmology for detecting and grading diabetic retinopathy. Diabetes Care 2002 Aug;25(8):1384-1389. [doi: 10.2337/diacare.25.8.1384] [Medline: 12145239]

15. Li Z, Wu C, Olayiwola JN, Hilaire DS, Huang JJ. Telemedicine-based digital retinal imaging vs standard ophthalmologic evaluation for the assessment of diabetic retinopathy. Conn Med 2012 Feb;76(2):85-90. [Medline: 22670358]

16. Mansberger SL, Gleitsmann K, Gardiner S, Sheppler C, Demirel S, Wooten K, et al. Comparing the effectiveness of telemedicine and traditional surveillance in providing diabetic retinopathy screening examinations: a randomized controlled trial. Telemed J E Health 2013 Dec;19(12):942-948 [FREE Full text] [doi: 10.1089/tmj.2012.0313] [Medline: 24102102]

17. Ahmed J, Ward TP, Bursell S, Aiello LM, Cavallerano JD, Vigersky RA. The sensitivity and specificity of nonmydriatic digital stereoscopic retinal imaging in detecting diabetic retinopathy. Diabetes Care 2006 Oct;29(10):2205-2209. [doi: 10.2337/dc06-0295] [Medline: 17003294]

18. Vujosevic S, Benetti E, Massignan F, Pilotto E, Varano M, Cavarzeran F, et al. Screening for diabetic retinopathy: 1 and 3 nonmydriatic 45-degree digital fundus photographs vs 7 standard early treatment diabetic retinopathy study fields. Am J Ophthalmol 2009 Jul;148(1):111-118. [doi: 10.1016/j.ajo.2009.02.031] [Medline: 19406376]

19. Schiffman RM, Jacobsen G, Nussbaum JJ, Desai UR, Carey JD, Glasser D, et al. Comparison of a digital retinal imaging system and seven-field stereo color fundus photography to detect diabetic retinopathy in the primary care environment. Ophthalmic Surg Lasers Imaging 2005;36(1):46-56. [Medline: 15688971]

20. Lin DY, Blumenkranz MS, Brothers RJ, Grosvenor DM. The sensitivity and specificity of single-field nonmydriatic monochromatic digital fundus photography with remote image interpretation for diabetic retinopathy screening: a comparison with ophthalmoscopy and standardized mydriatic color photography. Am J Ophthalmol 2002 Aug;134(2):204-213. [doi: 10.1016/s0002-9394(02)01522-2] [Medline: 12140027]

21. Cunha LP, Figueiredo EA, Araújo HP, Costa-Cunha LV, Costa CF, Neto JD, et al. Non-mydriatic fundus retinography in screening for diabetic retinopathy: agreement between family physicians, general ophthalmologists, and a retinal specialist. Front Endocrinol (Lausanne) 2018;9:251 [FREE Full text] [doi: 10.3389/fendo.2018.00251] [Medline: 29867777]

22. Farley TF, Mandava N, Prall FR, Carsky C. Accuracy of primary care clinicians in screening for diabetic retinopathy using single-image retinal photography. Ann Fam Med 2008;6(5):428-434 [FREE Full text] [doi: 10.1370/afm.857] [Medline: 18779547]

23. Andonegui J, Serrano L, Eguzkiza A, Berástegui L, Jiménez-Lasanta L, Aliseda D, et al. Diabetic retinopathy screening using tele-ophthalmology in a primary care setting. J Telemed Telecare 2010;16(8):429-432. [doi: 10.1258/jtt.2010.091204] [Medline: 20813892]

24. Government of the United Kingdom. 2017 Jan. Diabetic Eye Screening: Programme Overview URL: $\underline{\text { https://www.gov.uk/ }}$ guidance/diabetic-eye-screening-programme-overview [accessed 2019-02-27]

25. Nguyen HV, Tan GS, Tapp RJ, Mital S, Ting DS, Wong HT, et al. Cost-effectiveness of a national telemedicine diabetic retinopathy screening program in Singapore. Ophthalmology 2016 Dec;123(12):2571-2580. [doi:

10.1016/j.ophtha.2016.08.021] [Medline: 27726962]

26. RKKP. Nationwide Clinical Quality Database for Screening of Diabetic Retinopathy and Maculopathy (Diabase). Article in Danish. Landsdækkende Klinisk Kvalitetsdatabase for Screening Af Diabetisk Retinopati Og Maculopati (Diabase) 
URL: https://www.rkkp.dk/om-rkkp/de-kliniske-kvalitetsdatabaser/Landsdaekkende-klinisk-kvalitetsdatabase-for-screeningaf-diabetisk-retinopati-og-maculopati/ [accessed 2019-03-27]

27. Qualifications in Diabetic Retinopathy Screening. URL: http://www.drsdiploma.org/index.asp [accessed 2019-02-10]

28. Kirkizlar E, Serban N, Sisson JA, Swann JL, Barnes CS, Williams MD. Evaluation of telemedicine for screening of diabetic retinopathy in the Veterans Health Administration. Ophthalmology 2013 Dec;120(12):2604-2610. [doi:

10.1016/j.ophtha.2013.06.029] [Medline: 24084501]

29. Ribeiro L, Oliveira CM, Neves C, Ramos JD, Ferreira H, Cunha-Vaz J. Screening for diabetic retinopathy in the central region of Portugal. Added value of automated 'disease/no disease' grading. Ophthalmologica 2014 Nov 26 [Online ahead of print]. [doi: 10.1159/000368426] [Medline: 25427567]

30. Tufail A, Kapetanakis VV, Salas-Vega S, Egan C, Rudisill C, Owen CG, et al. An observational study to assess if automated diabetic retinopathy image assessment software can replace one or more steps of manual imaging grading and to determine their cost-effectiveness. Health Technol Assess 2016 Dec;20(92):1-72 [FREE Full text] [doi: 10.3310/hta20920] [Medline: 27981917]

31. Tufail A, Rudisill C, Egan C, Kapetanakis VV, Salas-Vega S, Owen CG, et al. Automated diabetic retinopathy image assessment software: diagnostic accuracy and cost-effectiveness compared with human graders. Ophthalmology 2017 Mar;124(3):343-351 [FREE Full text] [doi: 10.1016/j.ophtha.2016.11.014] [Medline: 28024825]

32. The Government of UK. 2016 Mar. The Management of Grading Quality: Good Practice in the Quality Assurance of Grading URL: https://assets.publishing.service.gov.uk/government/uploads/system/uploads/attachment data/file/512832/ The_Management_of_Grading.pdf [accessed 2019-02-10]

33. Ruamviboonsuk P, Teerasuwanajak K, Tiensuwan M, Yuttitham K, Thai Screening for Diabetic Retinopathy Study Group. Interobserver agreement in the interpretation of single-field digital fundus images for diabetic retinopathy screening. Ophthalmology 2006 May;113(5):826-832. [doi: 10.1016/j.ophtha.2005.11.021] [Medline: 16650679]

34. Kirkwood BJ, Coster DJ, Essex RW. Ophthalmic nurse practitioner led diabetic retinopathy screening. Results of a 3-month trial. Eye (Lond) 2006 Feb;20(2):173-177. [doi: 10.1038/sj.eye.6701834] [Medline: 16254596]

35. Public Health England. The Government of UK. 2017 Dec 8. Diabetic Eye Screening: Education and Training URL: https:/ /www.gov.uk/guidance/diabetic-eye-screening-education-and-training [accessed 2020-02-17]

36. The Scottish Diabetic Retinopathy Screening Programme. 2007. Scottish DRS Collaborative URL: https://www. ndrs.scot.nhs.uk/wp-content/uploads/2013/04/Grading-Scheme-2007-v1.1.pdf/ [accessed 2020-02-10]

37. Boucher MC, Bélair ML. Conception and evaluation of a module for training readers in screening for diabetic retinopathy using non-mydriatic digital photography. Invest Ophthalmol Vis Sci 2004 May;45(13):5248 [FREE Full text]

38. Landis JR, Koch GG. The measurement of observer agreement for categorical data. Biometrics 1977 Mar;33(1):159-174. [Medline: $\underline{843571]}$

39. Stellingwerf C, Hardus PL, Hooymans JM. Two-field photography can identify patients with vision-threatening diabetic retinopathy: a screening approach in the primary care setting. Diabetes Care 2001 Dec;24(12):2086-2090. [doi: 10.2337/diacare.24.12.2086] [Medline: 11723088]

40. McKenna M, Chen T, McAneney H, Membrillo MA, Jin L, Xiao W, et al. Accuracy of trained rural ophthalmologists versus non-medical image graders in the diagnosis of diabetic retinopathy in rural China. Br J Ophthalmol 2018 Nov;102(11):1471-1476. [doi: 10.1136/bjophthalmol-2018-312440] [Medline: 29973366]

41. Bhargava M, Cheung CY, Sabanayagam C, Kawasaki R, Harper CA, Lamoureux EL, et al. Accuracy of diabetic retinopathy screening by trained non-physician graders using non-mydriatic fundus camera. Singapore Med J 2012 Nov;53(11):715-719 [FREE Full text] [Medline: 23192497]

42. Goatman KA, Philip S, Fleming AD, Harvey RD, Swa KK, Styles C, et al. External quality assurance for image grading in the Scottish Diabetic Retinopathy Screening Programme. Diabet Med 2012 Jun;29(6):776-783. [doi: 10.1111/j.1464-5491.2011.03504.x] [Medline: 22023553]

43. Patra S, Gomm EM, Macipe M, Bailey C. Interobserver agreement between primary graders and an expert grader in the Bristol and Weston diabetic retinopathy screening programme: a quality assurance audit. Diabet Med 2009 Aug;26(8):820-823. [doi: 10.1111/j.1464-5491.2009.02767.x] [Medline: 19709153]

44. Canadian Ophthalmological Society Diabetic Retinopathy Clinical Practice Guideline Expert Committee, Hooper P, Boucher MC, Cruess A, Dawson KG, Delpero W, et al. Canadian ophthalmological society evidence-based clinical practice guidelines for the management of diabetic retinopathy - executive summary. Can J Ophthalmol 2012 Apr;47(2):91-96. [doi: 10.1016/j.jcjo.2012.01.022] [Medline: 22560411]

45. British Diabetic Association. Retinal Photography Screening for Diabetic Eye Disease: A British Diabetic Association Report. London: British Diabetic Association; 1997.

46. UK National Screening Committee. Dr Gerard Bulger and some achive URLS. 2007 Aug. Essential Elements in Developing a Diabetic Retinopathy Screening Programme URL: https://bulger.co.uk/dacorumhealth/daccom/PDF\%20Documents/ Diabetic\%20Retinopathy\%20Screening\%20(Workbook\%20R4.1\%202Aug07).pdf [accessed 2019-02-10]

47. Moss SE, Klein R, Kessler SD, Richie KA. Comparison between ophthalmoscopy and fundus photography in determining severity of diabetic retinopathy. Ophthalmology 1985 Jan;92(1):62-67. [doi: 10.1016/s0161-6420(85)34082-4] [Medline: 2579361] 
48. Oke JL, Stratton IM, Aldington SJ, Stevens RJ, Scanlon PH. The use of statistical methodology to determine the accuracy of grading within a diabetic retinopathy screening programme. Diabet Med 2016 Jul;33(7):896-903 [FREE Full text] [doi: 10.1111/dme.13053] [Medline: 26666463]

49. Erginay A, Chabouis A, Viens-Bitker C, Robert N, Lecleire-Collet A, Massin P. OPHDIAT: quality-assurance programme plan and performance of the network. Diabetes Metab 2008 Jun;34(3):235-242. [doi: 10.1016/j.diabet.2008.01.004] [Medline: $\underline{18424210}$ ]

\section{Abbreviations}

DD: disc diameter

DME: diabetic macular edema

ETDRS: Early Treatment Diabetic Retinopathy Study

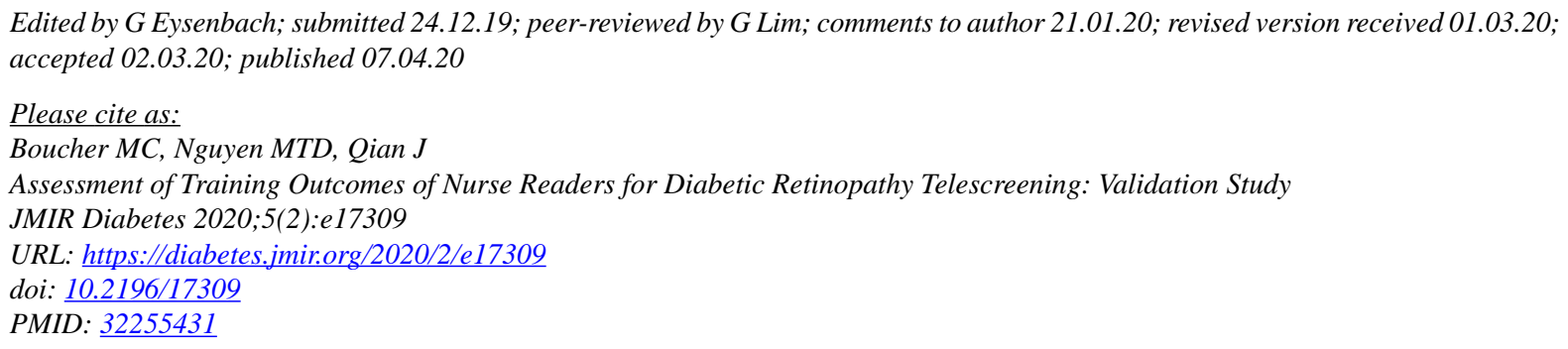

CMarie Carole Boucher, Michael Trong Duc Nguyen, Jenny Qian. Originally published in JMIR Diabetes (http://diabetes.jmir.org), 07.04.2020. This is an open-access article distributed under the terms of the Creative Commons Attribution License (https://creativecommons.org/licenses/by/4.0/), which permits unrestricted use, distribution, and reproduction in any medium, provided the original work, first published in JMIR Diabetes, is properly cited. The complete bibliographic information, a link to the original publication on http://diabetes.jmir.org/, as well as this copyright and license information must be included. 